and thus keeping the endometrium in a markedly congested state, causes the menorrhagia to which your attention has been directed. The pain in the right and left sides of which the patient complains is probably due to intercostal neuralgia, which no doubt results entirely from the bad blood state of the woman.

"This case serves to show, then, the method which I hope you will adopt in your examination of patients. In many instances where we would not expect to find any uterine disease it can be detected in this way. Begin, therefore, at the beginning, and inquire about every organ; just as a magistrate, in looking for the perpetrator of some murder, will make as many arrests as possible, in the hope of fixing the crime upon some one of the individuals.

"A word now in conclusion in regard to the condition of the endometrium. In cases of this kind we are exceedingly apt to have the lining membrane of the uterus covered with little fungoid growths, which give rise to very profuse hæmorrhages; and their existence has already been proved here by the use of the copper wire curette, an instrument with which I would advise that the whole cavity of the uterus be gently scraped, for the purpose of removing all these small excrescences. It is often astonishing to see to what an extent hamorrhage cau be controlled by this simple means."

Original inticleg.
AUTOPSY OF A CASE OF TRANSPOSITION
OF THE VISCERA.1

BX H. Adgustus wilson, M. D.,

Pathologist to the Presbyterian Hospital and Ophthalmic and Aural Surgeon to St. Mary's Hospital, Philadelphia.

THE comparatively rare occurrence of the phenomena, an instance of which $I$ am about to relate, will be, I think, sufficient excuse for occupying the time of the College. I regret that $I$ am not able to offer a more complete record of the case; but a careful dissection was impossible without taking an unwarranted risk of septic poisoning, as the abdominal cavity was filled with fetid pus.

Frank M., aged twenty-one, died at the Presbyterian Hospital of purulent peritonitis. I shall ignore in this paper the pathological conditions found at the post-mortem examination, inasmuch as they have no bearing upon the subject under consideration.

The patient had been aware since boyhood that his heart was misplaced, and upon one occasion a physician told him that that was the reason be was lefthanded. He had never been very strong; but it does not appear that he ever had any serious affection; the cause of which could be assigned to his misplaced viscera.

In 1878, when he first came to the hospital, Dr. James Markoe, under whose care he was, noticed that not only was his heart perceptible in the fifth interspace of the right side, but also by percussion ascertained that this organ occupied the same relative position upon the right side that it should upon the left. He found also that the liver and spleen were transposed, but no further changes seem to have been noticed.

At the time I made the post-mortem examination, I found externally nothing to indicate the great changes in the positions of the internal organs, except that the

1 Read before the Philadelphia College of Physicians, October 4, 1882. right testicle was suspended at a lower level than the left. When I had opened the thorax and abdomen and laid bare the organs contained therein, the appearance to me was as though I was looking at the body reflected in a mirror. It was like the photographer's negative.

The heart first attracted my attention, and was found to be normal in every respect, but occupying, as already noted, a position upon the right side. It looked as though it had been pushed over to its present position without changing materially its relations with other organs. The right side was the pulmonary side and the left the systemic side, and in this respect the organ performed its function in a normal manner. The aorta starting from the left ventricle followed a somewhat irregular course, crossing over the right bronchus and going from there to the right side of the vertebral column, along which it descended upon the right side. The branches given off from the arch of the aorta were the two coronary arteries unchanged, the innominate going up the left side of the neck and giving off the left common carotid and left subclavian. While coming from the right portion of the arch were the right common carotid and right subclavian.

The lungs were reversed. The right lung was found to be smaller, to allow space for the heart. It had two lobes.

The left lung corresponded in appearance to what is commonly the right lung, was shorter than its fellow, being pressed up by the liver, was broader, and had three lobes.

In the abdominal cavity the liver occupied the left hypochondriac and partly the epigastric regions, the large lobe to the left and the smaller ones to the right, the gall-bladder and everything else similiarly changed.

The stomach and intestines were transposed. The stomach was partly in the right hypochondrium and partly in the epigastric region. The pylorus extended forward and downward toward the middle of the abdomen. The spleen was on the right side, and attached to the greater curvature of the stomach.

The crecum was situated in the left iliac fossa, and the colon ascended on the left side and crossed from left to right side of the abdomen. From there it descended and terminated in the sigmoid flexure upon the right side.

As already stated, the man was naturally lefthanded. Hyrtl was the first. I believe, to advance the theory that we are normally right-handed because of the more direct flow of blood to the brain upon the left side. And this theory would be substantiated if all cases where the heart and great vessels were transposed were left-handed; but such is not the case. A few years ago a theory was advanced that right-handedness depended upon natural selection. But the easiest explauation is that from earliest infancy we are instructed to use the right hand always in preference to the left. When a person with transposition of the viscera is left-handed we may call it a coincidence. In any other view, it would be extremely difficult to account for the far larger number of persons whose organs are arranged normally and yet are left-handed. In the cases that are noted in the journals I have not been able to find statistics enough to draw any inferences, for, when this condition is noted, right-handedness appears to be as frequently met with as left-handedness in cases where the viscera are transposed.

Peacock, in his monograph on Malformations of the 
Heart ${ }^{1}$ says that the most common of all the internal displacements is that in which the beart is placed upon the right side in a position corresponding to that which it should occupy upon the left, and that this displacement is almost always associated with more or less complete transposition of other viscera. Occasionally the heart is transposed while the other organs are unchanged. ${ }^{2}$

Among the earliest recorded cases are those of Servius and Schenkius in Rome in $1643,{ }^{\circ}$ and one by Riolan in 1652.4

The first case recorded in which the malformation was noticed during life appears to be that described by Morand ${ }^{5}$ in 1666 . This case seems to have attracted considerable attention at the time, and was said to have suggested to Molière the transposition of the heart and liver which he puts into the mouth of Sganarelle in his play of Le Mèdecin Malgré lui, published about the time this case was reported.

In cases of more or less complete transposition, the arteries, if they do not retain their natural positions, may be displaced in almost all conceivable ways.

Dr. Gamage ${ }^{6}$ reported a case in which the aorta arose from the right ventricle and the pulmonary arteries from the left ventricle. Mr. Abernethy ${ }^{7}$ saw a child ten months old, where the portal veins terminated in the vena cava, the liver being supplied from an unusually large bepatic artery. Mr. Douglas Fox ${ }^{8}$ reported the result of a post-mortem examination in a case where the heart was transposed, and the aorta, after crossing the right bronchus, passed behind the lower end of the trachea, over the vertebral column, and pursued its usual course from there down the left of the spine.

For a very complete account of a case similar to the one I now report, and for an exhaustive study of the histology of such malformations, I will refer to Dr. Allen Thompson's paper in the Glasgow Medical Journal, vol. p. 220.

As regards the practical application of this case, it would be well to bear such abnormality in mind as a possible condition in cases brought to a physician's notice in an unconscious condition. It will readily be seen that considerable difficulty might arise in forming a diagnosis. In surgical operations upon thorax or abdomen it would prove a serious complication, as, for instance, in colotomy, paracentesis abdominis, or pericardii.

\section{REPORT OF A CASE OF HOMICIDE. ${ }^{9}$}

BX C. C. TOWER, M. D., MEDICAL EXAMINER, SOUTH WEYMOUTH.

ON the evening of Thursday, July 7, 1881, I was notitied by the selectmen of Braintree that the dead body of a person had been found in that town under circumstances which justified a supposition of violence.

1 T. Peacock, Malformations of the Heart, $2 d$ ed., 1866.

2 Sur l'Ectopie de l'appareil de la circulation et particulièrement sur celle/du cœur.f- Rep. Gen. d'Anat. et de Phys. Pathol., t. ii., 1826, p. 1 .

${ }_{8}$ Thomas Bartbolinus, Hist. Anat. Cent., ii. 29. Amstelodami, 1654.

4 Allen Thompson, Glasgow Medical Journal, vol. i., 1853, p. 220.

5 Méry, Memoirs of Academy of Paris for 1866.

6 N. Eng. Journ. Med. and Surg., iv., 1815, p. 244.

7 Philosophic Trans, 1793, p. 59.

8 Lond. Med. and Phys. Journ., vol. li., 1824, p. 474.

9 Read before the Massachusetts Medico-Legal Society, at the An nual Meeting June 13, 1882.
I immediately proceeded to the place where the body lay, which I reached shortly after nine o'clock. 'The night was cloudy and quite dark, requiring the use of lanterns to inspect the remains.

The body was that of a man five feet five inches in height, and, as I learned on inquiry, of an average weight of one hundred and forty pounds. It was lying in a recently mown field of grass four feet west from a high stone wall and parallel to it, the head being directed towards the south. Ten feet distant, in a northerly direction, was a farm-gate which opened into the field from a public highway called I iberty Street. No missiles, weapons, or other instruments of violence were discovered in the vicinity of the corpse. The position was right dorsal, the head being slightly turned to the left, the face looking upwards. The right arm was bent at the elbow, the forearm being elevated at an angle of nearly ninety degrees. The left arm was slightly flexed, the hand resting on the left hip. The right leg was strongly flexed, the foot lying beneath the left knee-joint. The left leg was extended.

The clothing consisted of vest, pants, and white cotton shirt, the sleeves of the latter being unbuttoned, ripped at the seams, and turned backwards underneath the shoulders. The head and feet were uncovered, the soles of the latter soiled and hardened, indicating that the deceased had been traveling barefoot.

The body was in a considerably advanced state of putrefaction and emitted a strong stench. The features were swollen and distorted beyond recognition; the color blackish, resembling that of a negro. Numberless larva in an active state covered the mouth and nostrils. The eyelids were wide open, the humors of the eye apparently coagulated and projecting in a spiral form from the corneæ. The scalp, particularly over the left parietal region, was emphysematous and softened. The upper lip presented at one point a slight protuberance, but no solution of continuity on its outer or inner surface. The teeth were secure and the tongue entire. The forefinger of the right hand bore marks of previous amputation, which, with a scar on the left arm, were the principal signs by which the remains were recognized.

The clothing having been removed, the skin covering the chest and abdomen presented a greenish-brown color, the cuticle being separated in small patches from the underlying derma by bloody serous fluid and by bubbles of gas of putrefaction. 'The whole trunk was greatly distended, so that when the clothing was unbuttoned it snapped apart and could not easily be brought together again. The scrotum and penis were enormously swollen, the latter spirally twisted.

Not having with me my rubber gloves a short piece of lath was used to remove the maggots, and in a measure assist in the examination of the body. Every portion of the body externally was carefully inspected, the corpse being turned one way and the other to fully expose every part. The sphincter ani was relaxed, and considerable fecal matter covered the adjoining region. No external mark of violence was anywhere found. The skin was nowhere broken, and the examination thus far failed to reveal any fractured bones.

On inquiry, I learned that the dead body had been discovered about three hours before my arrival by a person walking along the street whose attention was directed to it by the offensive smell. I learned also that the remains were those of William McCornish, a laborer, employed up to Saturday night of July $2 d$ at a 